\section{D) Check for updates}

Cite this: Org. Chem. Front., 2019, 6 3603

DOI: $10.1039 / c 9 q 090089 f$

rsc.li/frontiers-organic

\title{
Retraction: A miraculous chiral Ir-Rh bimetallic nanocatalyst for asymmetric hydrogenation of activated ketones
}

\author{
Xiuru Xue, Zhaohui Zhao and Yanhua Wang*
}

Retraction of 'A miraculous chiral Ir-Rh bimetallic nanocatalyst for asymmetric hydrogenation of activated ketones' by Xiuru Xue et al., Org. Chem. Front., 2018, 5, 3585-3589.

\begin{abstract}
We, the named authors, hereby wholly retract this Organic Chemistry Frontiers article due to concerns with the reliability of the NMR spectra in the published article. Upon repetition of the experiments, the authors found that the ${ }^{1} \mathrm{H}-\mathrm{NMR}$ spectra of compounds 1 and 2 provided in the published article were different in splitting pattern and/or chemical shifts from their duplicated experiments. As the findings are unreliable, we are therefore retracting this article to maintain the accuracy of the scientific record.
\end{abstract}

Signed: Xiuru Xue, Zhaohui Zhao and Yanhua Wang, 20th September 2019.

Retraction endorsed by Wenjun Liu, Executive Editor, Organic Chemistry Frontiers. 